\title{
Mudança estrutural no setor cotonicultor brasileiro: Uma análise da territorialização no cerrado brasileiro e do impacto do contencioso do algodão
}

Isabela Barchet isabelabarchet@hotmail.com Universidade Estadual do Oeste do Paraná (UNIOESTE), Cascavel, Paraná, Brasil.

Alberto Alves da Rocha albertodarocha@hotmail.com Universidade Estadual do Oeste do Paraná (UNIOESTE), Cascavel, Paraná, Brasil.

\section{Camili Dal Pai}

camili.dpp@gmail.com

Universidade Estadual do Oeste do Paraná (UNIOESTE), Cascavel,

Paraná, Brasil.

\section{RESUMO}

Este estudo objetivou discutir a nova territorialização da produção do algodão brasileiro, a partir do colapso na década de 1990, por meio técnico-científicoinformacional e investigar uma possível mudança estrutural no setor após 2002, principalmente em decorrência da ação movida pelo Brasil na OMC, denominada contencioso do algodão, contra os subsídios adotados pelos EUA na produção dessa commodity. Para abonar tais resultados, utilizou-se o teste de Chow de forma a verificar a mudança estrutural na quantidade produzida e no volume exportado de algodão brasileiro, tendo como hipótese a identificação do ano em que ocorreu tal ruptura institucional. Dentro desse contexto, evidenciou-se a mudança de estrutura, principalmente no volume exportado de algodão, desde o ano em questão e uma reorganização do espaço produtivo na formação de um novo território construído para a cotonicultura brasileira.
\end{abstract}

PALAVRAS-CHAVE: Comércio internacional. Mudança estrutural. Territorialização. Meio técnico-científico-informaciona. 


\section{INTRODUÇÃO}

O Brasil, acompanhando os maiores produtores, foi responsável pela quinta maior produção mundial de algodão em 2011. China, Índia e Estados Unidos da América (EUA) produziram naquele período cerca de $60 \%$ do algodão mundial, ocupando as três posições de liderança (FAO, 2013). Em termos de distribuição espacial da produção brasileira, há uma concentração significativa em Mato Grosso e região Oeste da Bahia, que em 2011 representaram 81\% da área colhida nacional e $81 \%$ da quantidade produzida da fibra no país (IBGE, 2013), garantindo a autossuficiência brasileira na produção com excedente para a exportação.

Todavia, em termos gerais, a desregulamentação do mercado nacional a partir dos anos 1990 incidiu em um aumento das taxas de juros e na redução dos prazos para pagamento de créditos agrícolas. Além disso, a eliminação de tarifas alfandegárias no setor cotonicultor, que foram reduzidas de $55 \%$ para zero, e o ataque do bicudo-do-algodoeiro (Anthonomusgrandis) contribuíram para desmantelar a cadeia produtiva do algodão brasileiro, desestruturando e inviabilizando o modelo de produção que existia nas Regiões Nordeste, Sul e Sudeste (SANTOS; SANTOS, 1997).

Assim, na década de 1990, o Brasil passou a ser um grande importador de fibra de algodão. Nesse período o governo americano e os países europeus expandiram os subsídios para as produções locais de pluma e, diante dos preços artificialmente baixos, se estabeleceu uma vantagem em importar em detrimento de se produzir internamente. Ao mesmo tempo, o Brasil sofria com um cenário econômico de inflação elevada, podendo então beneficiar-se do diferencial de taxas de juros reais, em torno de $6 \%$ a $8 \%$ ao ano e prazo dilatado em 360 dias. Conjuntamente:

(...) a partir de 1988/89 que o consumo se efetivou como superior à produção nacional. Assim, a partir de 1991/92, o Brasil começa a aparecer entre os 10 maiores países importadores de algodão, ocupando o terceiro lugar em 1992/93 e 1993/94, e o quinto lugar em 1994/95 (SANTOS; SANTOS, 1997).

A partir de meados dos anos 1990, a cotonicultura brasileira seguiu o caminho aberto pela expansão da cultura da soja em direção ao Cerrado brasileiro, aproveitando das estruturas de transferência (transporte, comunicação e energia), das condições naturais e geoeconômicas, dos programas estaduais de incentivos fiscais, do desenvolvimento de novas tecnologias e da pesquisa biotecnológica de novos cultivares adaptados e resistentes. Na década de 2000 a cultura do algodão se estabelece em Mato Grosso, Goiás e Bahia retomando o crescimento e indicando um novo reordenamento espacial e produtivo no país.

Para Borges (2007) "a condição da localização atual está baseada na indústria de alta tecnologia que impõe uma trajetória de crescimento intensiva em conhecimento e requer uma infraestrutura de natureza diferente da anterior". Isso demonstra que a mudança territorial do algodão se deu em busca de novos espaços que permitissem a aplicação das novas tecnologias de produção, com o 
propósito de aumentar a produtividade e elevar a competitividade da pluma nacional. A Figura 1 apresenta o histórico da área plantada de algodão por região brasileira.

Figura 1 - Histórico da área plantada de algodão (em mil ha)

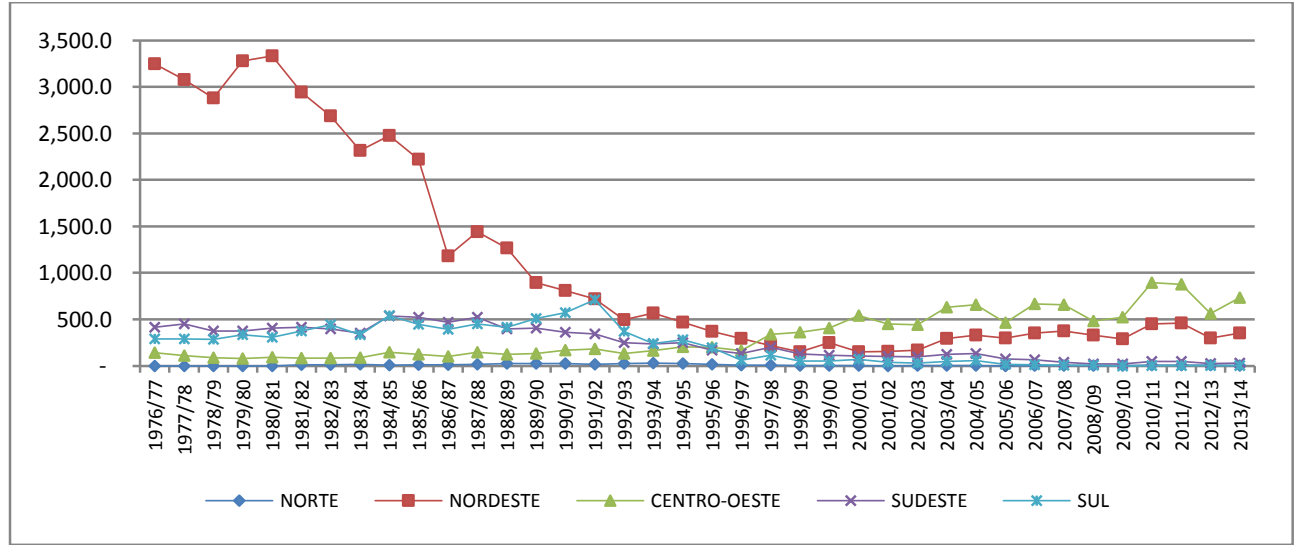

Fonte: elaboração própria a partir de dados históricos da Conab (2014)

A figura acima representa a linha de tempo das áreas ocupadas pela cotonicultura e demonstra a ação do meio técnico-científico-informacional na desterritorialização desta cultura, ocorrida nos estados da Região Nordeste, no Mato Grosso do Sul, Goiás Minas Gerais, São Paulo e Paraná, até o ano de 1995. Data desse período o colapso na produção, sendo que sua retomada ocorreu apenas no ano de 2000 com outra dinâmica, novas tecnologias e outra territorialização, deslocando-se para o Mato Grosso e região Oeste da Bahia. A Figura 2 ilustra essa afirmação.

Figura 2 - Histórico da produção de algodão em caroço por Grande Região (kg/ha)

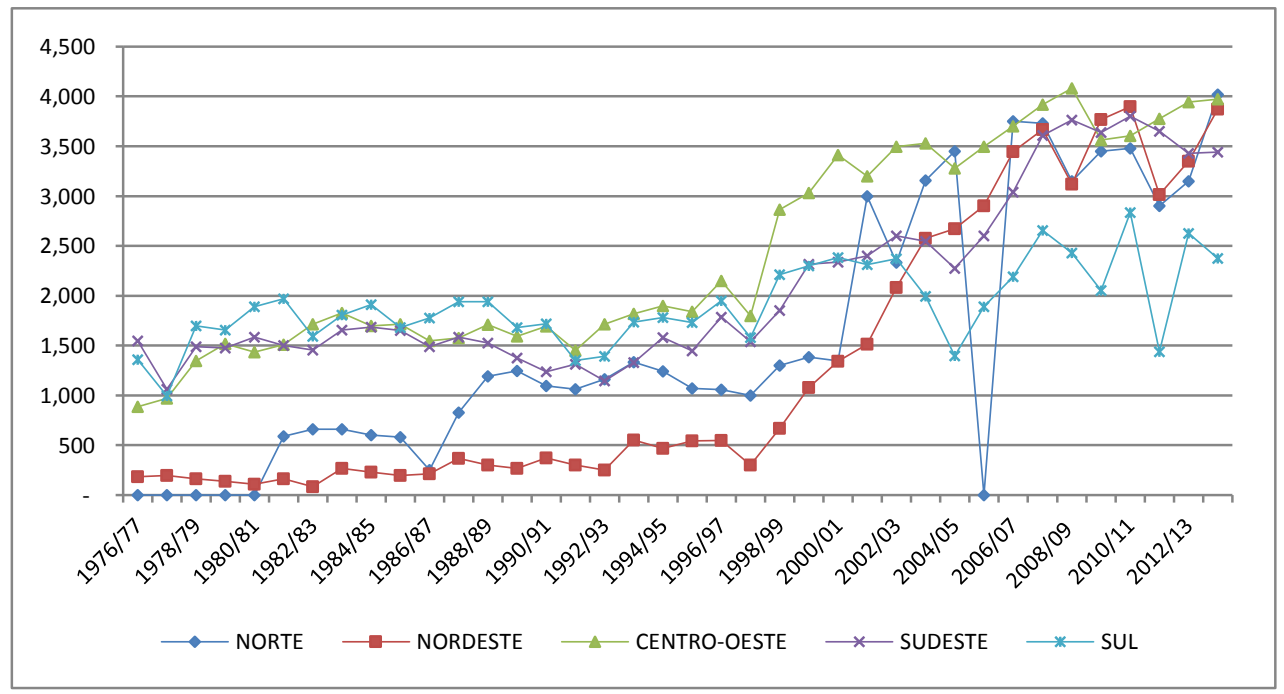

Fonte: elaboração própria a partir de dados históricos da Conab (2014)

A Figura 2 complementa a informação anterior, evidencia que a ação do meio técnico-científico-informacional proporcionou, a partir do ano 2000, a territorialização da cotonicultura brasileira tecnificada, produtiva e competitiva. Nesse cenário não havia mais espaço para a produção artesanal e de baixo uso 
tecnológico, o que estabeleceu o rearranjo produtivo no Cerrado brasileiro. Para Moreira (2008) o rearranjo que ocorre no espaço, que sai de uma espacialidade baseada em um complexo agrícola para outra, apoiada numa arrumação regional de cultivares, é o desenvolvimento da divisão internacional do trabalho e das trocas, cujos propósitos os pedaços do espaço terrestre vão se regionalizando por produto.

No que se refere ao comércio internacional, dados da FAO (2013) apontam que em 2010 os Estados Unidos ocuparam a liderança nas exportações mundiais com uma representatividade de mercado de $35 \%$, o segundo maior exportador foi a Índia com $8 \%$ dos embarques, a Austrália representou o terceiro maior exportador mundial com $5 \%$ de participação total, cifra muito próxima do quarto maior exportador, o Brasil, com $5 \%$ dos embarques mundiais.

Esse cenário ilustra a dinâmica do setor, com alta concentração de mercado e liderança dos Estados Unidos no comércio internacional, presumindo de certo modo a influência deste sobre o equilíbrio dos preços da commodity. Porém, segundo Ferreira Filho, Alves e Villar (2009) a competitividade americana é artificial, uma vez que se ampara na política de subsídios praticada no país, haja vista que seu sistema produtivo apresenta baixa produtividade e custos relativamente altos. Os autores afirmam ainda que, caso tais concessões fossem suprimidas, a produção sofreria uma queda significativa, o que refletiria diretamente na elevação dos preços internacionais.

Pan et. al. (2004) corroboram o posicionamento dos autores, afirmam que caso os subsídios fossem eliminados completamente, a produção americana sofreria uma queda de 630 mil fardos, o que pressionaria uma elevação de preços. Nesse cenário, os países mais beneficiados seriam Brasil, Austrália e países do Oeste Africano que, dada uma elevação em sua produção, provocariam uma nova redução no preço internacional do algodão.

Frente a esse contexto, no início da década de 2000, o Brasil recorreu à Organização Mundial do Comércio (OMC) com o intuito de mover uma ação contra o governo dos Estados Unidos da América (EUA) a fim de denunciar a política de subsídios americana concedidos aos produtores e exportadores de algodão. Ressalta-se que as políticas protecionistas direcionadas aos cotonicultores dos EUA acabam por influenciar os preços internacionais dessa commodity, provocando distorções no mercado mundial e afetando não apenas o Brasil, mas igualmente outros países produtores.

Por consequência, os efeitos negativos dessas medidas se materializam na forma de redução na renda dos agricultores, retração dos investimentos no setor, além de contribuírem para o baixo desempenho econômico das nações em desenvolvimento (JALES, 2010; COSTA, BUENO, 2004; SEN, 2010). Destaca-se ainda que:

(...) o mercado é cada vez mais mundial, dando ao produto nova mobilidade espacial. São elementos que apontam para uma mudança do sentido do lugar, mas sem esconder o fato de que o processo de globalização realiza-se aprofundando as contradições entre o local e o mundial, reafirmando e aprofundando a desigualdade espacial gestada no seio da produção capitalista (CARLOS, 2007). 
Em suma, a medida denunciada pelo Brasil baseia-se na verificação de que o incentivo adotado pelos EUA representa um tratamento desigual em relação aos demais países, principalmente os países em desenvolvimento, pois, diante da impossibilidade fiscal, não podem oferecer os mesmos benefícios aos seus produtores e exportadores. Tais medidas afetam os custos relativos de produção e, dada a pressão sobre a oferta, alteram os preços internacionais, tornando os países em desenvolvimento menos competitivos (PEREIRA, COSTA, ARAÚJO, 2012).

Em função disso, a ação movida pelo Brasil contra a medida protecionista dos EUA, denominada contencioso do algodão, é considerada uma conquista da política comercial brasileira e representa um exemplo de que a articulação entre o poder público e as associações ligadas ao setor cotonicultor pode representar um mecanismo de enforcement fundamental para a defesa dos interesses nacionais. Além de ser um alento para os demais países em desenvolvimento e produtores de algodão na transformação do cenário vivenciado pelos mesmos.

Diante do exposto, o objetivo deste estudo é discutir o rearranjo espacial da produção de algodão e os impactos do contencioso do algodão na configuração do setor no Brasil, vislumbrando uma possível mudança estrutural evidenciada por estudos empíricos. Especificamente pretende-se descrever e analisar a natureza da trajetória histórica da cotonicultura no Brasil; analisar a existência de uma mudança estrutural no setor cotonicultor brasileiro tendo como referência a abertura do contencioso na OMC e por fim, identificar se a nova territorialização da produção de algodão e a abertura da ação na OMC incorreu em uma alteração da configuração da cotonicultura brasileira.

Além desta introdução, o estudo está organizado em quatro seções. Incialmente será apresentado o método utilizado para compor o estudo, alicerçado no teste de Chow. Na segunda seção discorrer-se-á sobre a trajetória histórica do algodão e a configuração do setor cotonicultor pós-formação da OMC, por meio de diagramação estatística. A terceira seção destina-se a identificação e análise de uma possível mudança de estrutura no setor em análise oriunda do contencioso do algodão. Finalmente, na quarta e última seção serão realizadas as considerações finais sobre o estudo.

\section{ASPECTOS METODOLÓGICOS}

A construção de um novo território da cotonicultura no Cerrado brasileiro é marcada pela evolução do meio técnico-científico-informacional, isto é, por um processo no qual a ciência, a técnica e a informação são atuantes de forma interdependente em todos os aspectos da transformação do espaço. Este espaço foi, ao mesmo tempo, a condição e o resultado do processo de inovação técnica, produtiva e organizacional das necessidades de inovação e aumento da produtividade da pluma do algodão para competir em qualidade e preço no mercado internacional.

Entre as metodologias pautadas para testar uma presumível mudança estrutural, o marco inicial dos estudos consistiu no artigo de Chow (1960). Ao testar a hipótese de estabilidade de seu modelo, este se transformou no que é atualmente verificado como estudos de quebra estrutural. Nesse sentido, o teste 
de Chow verifica se alguns dos coeficientes do modelo mostam-se diferentes com relação a um subconjuntos de dados observados (DIAS; CASTRO JÚNIOR, 2003).

Segundo Gujarati (2006), o termo mudança estrutural designa que os valores dos parâmetros do modelo não se mantêm iguais durante todo o período considerado. Podendo a mudança estrutural decorrer de forças exógenas como mudanças na política econômica, medidas impostas ou por várias outras causas.

Dessa forma, o teste de Chow propõe calcular de forma separada regressões para cada conjunto de dados verificando a diferença nas equações estimadas. Caso essa diferença seja significativa, a mesma indica uma mudança estrutural na relação. Ressalta-se que o teste de Chow parte do princípio de que a data da mudança estrutural seja conhecida (GUJARATI, 2006).

Considerando a equação 1 descrita a seguir e tendo em vista que o teste de Chow divide a série de dados em dois subperíodos; o primeiro é composto pelas n1 primeiras observações (equação 2), o segundo é formado pelas n2 observações restantes (equação 3 ), ponderando que n1+n2 é igual a $n$.

$$
\begin{array}{r}
\boldsymbol{Y}_{\boldsymbol{i}}=\boldsymbol{\beta}_{\mathbf{1}}+\boldsymbol{\beta}_{\mathbf{2}} \boldsymbol{X}_{\boldsymbol{i} \mathbf{2}}+\boldsymbol{\beta}_{\mathbf{3}} \boldsymbol{X}_{\boldsymbol{i} \mathbf{3}}+\ldots+\boldsymbol{\beta}_{\boldsymbol{k}} \boldsymbol{X}_{\boldsymbol{i} \boldsymbol{k}}+\boldsymbol{\varepsilon}_{\boldsymbol{i}}(\boldsymbol{i}=\mathbf{1}, \ldots, \boldsymbol{n}) \\
Y_{i}=\alpha_{1}+\alpha_{2} X_{i 2}+\alpha_{3} X_{i 3}+\ldots+\alpha_{k} X_{i k}+u_{i}\left(i=1, \ldots, n_{1}\right) \\
\boldsymbol{Y}_{\boldsymbol{i}}=\boldsymbol{\gamma}_{\mathbf{1}}+\boldsymbol{\gamma}_{\mathbf{2}} \boldsymbol{X}_{\boldsymbol{i} \mathbf{2}}+\boldsymbol{\gamma}_{\mathbf{3}} \boldsymbol{X}_{\boldsymbol{i} \mathbf{3}}+\ldots+\boldsymbol{\gamma}_{\boldsymbol{k}} \boldsymbol{X}_{\boldsymbol{i} \boldsymbol{k}}+\boldsymbol{\xi}_{\boldsymbol{i}}\left(\boldsymbol{i}=\mathbf{1}, \ldots, \boldsymbol{n}_{\mathbf{2}}\right)
\end{array}
$$

Em outras palavras, a equação 1 pressupõe que não há diferença entre os dois períodos, ou seja, essa equação considera que o intercepto e o coeficiente angular da regressão permanecem os mesmos durante todo o período em análise, não verificando uma mudança estrutural. Em contrapartida, as equações 2 e 3 pressupõem que as regressões dos dois subperíodos são diferentes, denotando que o intercepto e os coeficientes angulares apresentam diferenças significativas.

A operacionalização do teste de Chow requer que o pressuposto de normalidade esteja contemplado, ou seja, que os erros de cada conjunto de observações dos subperíodos sejam distribuídos normalmente com médias zero e variância constante, além disso, tais erros devem distribuir-se de forma independente (GUJARATI, 2006). Estando os pressupostos de normalidade e independência dos resíduos contemplados, a operacionalização do teste de Chow segue com o desenvolvimento das seguintes etapas:

1) Estima-se a equação 1 a fim de obter os resíduos para denominá-los de S1 $=\Sigma \mathrm{ei} 2$;

2) Estima-se as equações (2) e (3) denominando seus resíduos de, respectivamente, S2 e S3. Como os resíduos dos subperíodos são independentes, pode-se obter $\mathrm{S} 4$, onde $\mathrm{S} 4=\mathrm{S} 2+\mathrm{S} 3$;

3) Determina-se a diferença entre S1 e S4 dada por S5 = S1 - S4

4) Testar as hipóteses $\mathrm{H} 1$ e HO conforme a estatística teste descrita abaixo.

HO: Ausência de mudança estrutural;

H1: Ocorrência de mudança estrutural.

Estatística teste: $\frac{S_{5} / k}{S_{4} / n_{1}+n_{2}-2 k} \sim F_{k, n_{1}+n_{2}-2 k}$, onde $\mathrm{K}$ é o número de parâmetros do modelo. 
Se Fcalculado for maior que Fcrítico rejeita-se a hipótese de estabilidade dos parâmetros, ou seja, há ocorrência de mudança estrutural.

Destaca-se que uma mudança estrutural pode significar mudanças de intercepto, mudança de inclinação ou, ainda, uma combinação de ambos, no entanto, o teste de Chow apenas permite inferir que os parâmetros das duas regressões em análise são diferentes, não permitindo inferir se essa diferença decorre dos interceptos, dos coeficientes angulares ou de ambos. Para tanto, procede-se a inclusão de variáveis dummy na regressão original (SULIANO; CAVALCANTE; ROCHA, 2009).

Assim, considerando que o presente estudo, por meio da operacionalização do teste de Chow, procura dar respaldo à identificação da possível mudança estrutural ocorrida no setor cotonicultor brasileiro tendo como ponto de referência a ação movida pelo Brasil contra a medida protecionista dos EUA, denominada contencioso do algodão, faz-se necessário o ajuste do modelo de regressão múltipla (equação 4) utilizando-se do método dos mínimos quadrados (GUJARATI, 2006).

$$
\begin{gathered}
Y_{i}=\beta_{0}+\beta_{1} \text { Tempo } \\
+\varepsilon_{i}
\end{gathered}
$$

Onde $Y i$ corresponde à variável do setor cotonicultor brasileiro; $\beta 0=$ intercepto; $\beta 1, \beta 2$ e $\beta 3=$ coeficientes angulares; Tempo = tempo da série histórica representado pelo número de anos $(0,1,2 \ldots)$; Mudança = variável dummy de diferença de intercepto referente à mudança estrutural do contencioso do algodão (0 para não ocorrência; 1 para ocorrência); Tempo. Mudança $=$ variável de interação (dummy e tempo para diferença de inclinação); $\varepsilon \mathrm{i}=$ resíduo.

O arcabouço metodológico descrito acima utiliza para sua operacionalização as séries históricas de quantidade produzida de algodão (QPA) e volume exportado de algodão (VEA), os dados abrangeram o período de 1990 a 20011 e 1995 a 2011, respectivamente. Dando ênfase, assim, ao período anterior e posterior a ação movida pelo Brasil contra a medida protecionista dos EUA, em setembro de 2002, denominada contencioso do algodão. A série histórica da quantidade produzida de algodão foi coletada junto ao Instituto Brasileiro de Geografia e Estatística no sistema de dados agregados (IBGE/SIDRA). A série histórica do volume de algodão exportado pelo Brasil foi obtida junto ao banco de dados estatísticos da FoodandAgricultureOrganization (FAOstat).

\section{A TRAJETÓRIA HISTÓRICA DO ALGODÃO BRASILEIRO PÓS-FORMAÇÃO DA OMC}

Esta seção tem por objetivo explicitar, mediante diagramação estatística, a evolução da produção de algodão no Brasil, sobretudo no período compreendido entre 1990 e 2011.

As informações apresentadas na Figura 3 referem-se a comparação entre a área colhida (ha) de algodão no Brasil e o valor da produção (em mil reais). Verifica-se a volatilidade na evolução da área colhida, que pode ser explicada pela variação nos preços e substituição pelo cultivo de outras culturas, sobretudo a soja e o milho. Os dados sinalizam recuperação em 2011, quando as variáveis obtiveram a maior expressividade ao longo da série histórica analisada. 
Figura 3 - Comparativo entre a área colhida $(\mathrm{Ha})$ e o valor da produção (mil R\$) Brasil (1995-2011)

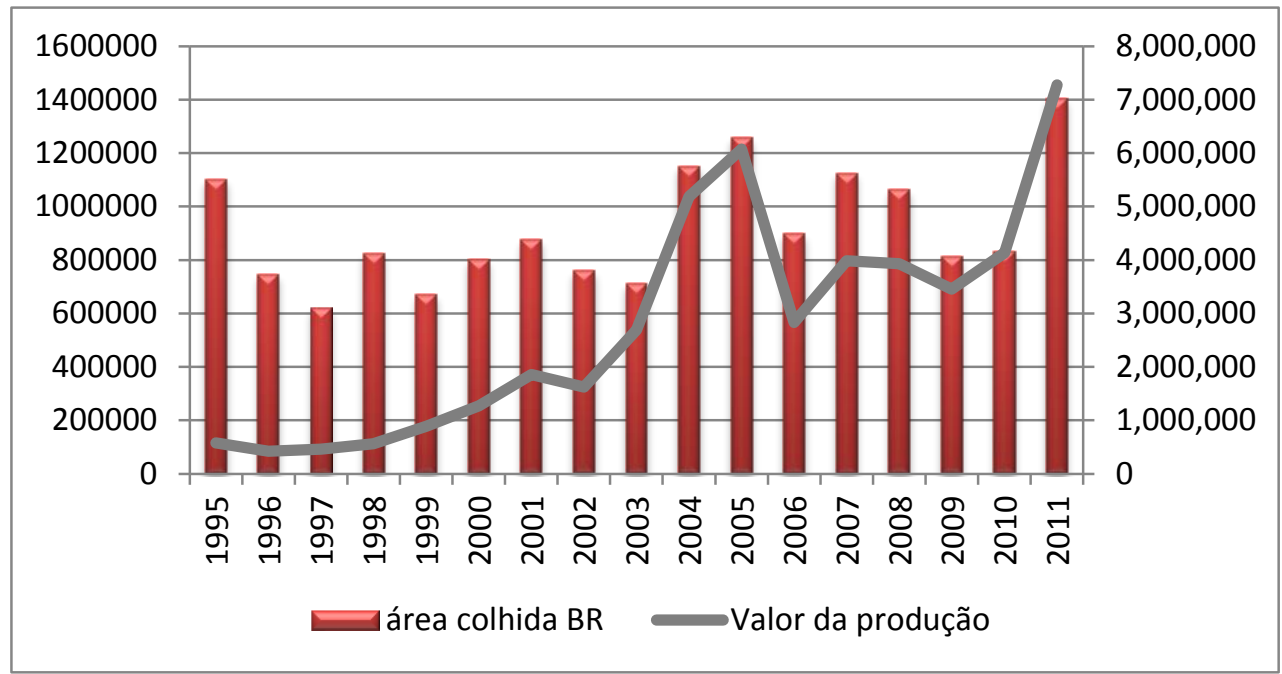

Fonte: elaboração própria a partir de IBGE (2013)

A análise dos dados sobre o valor da produção, dispostos na figura acima, particularizam três períodos. Entre 1995 e 2005 houve um incremento superior a $900 \%$ na evolução da variável. Após verificar um recorde no valor da produção em 2005, sofreu, em 2006, um expressivo decréscimo de 53,38\% acompanhando a queda de 28,6\% na área colhida. Em 2007 registrou-se uma inversão neste cenário, sinalizando um período de recuperação e crescimento do montante produzido da commodity, obtendo-se um novo recorde em 2011, período em que os preços apresentaram o maior valor na série histórica conforme demonstrado na Figura 4. A variação no valor da produção entre 2006 e 2011 foi de mais de $150 \%$.

Figura 4 - Evolução dos preços ao produtor no Brasil 1995-2011 (em US\$/tonelada)

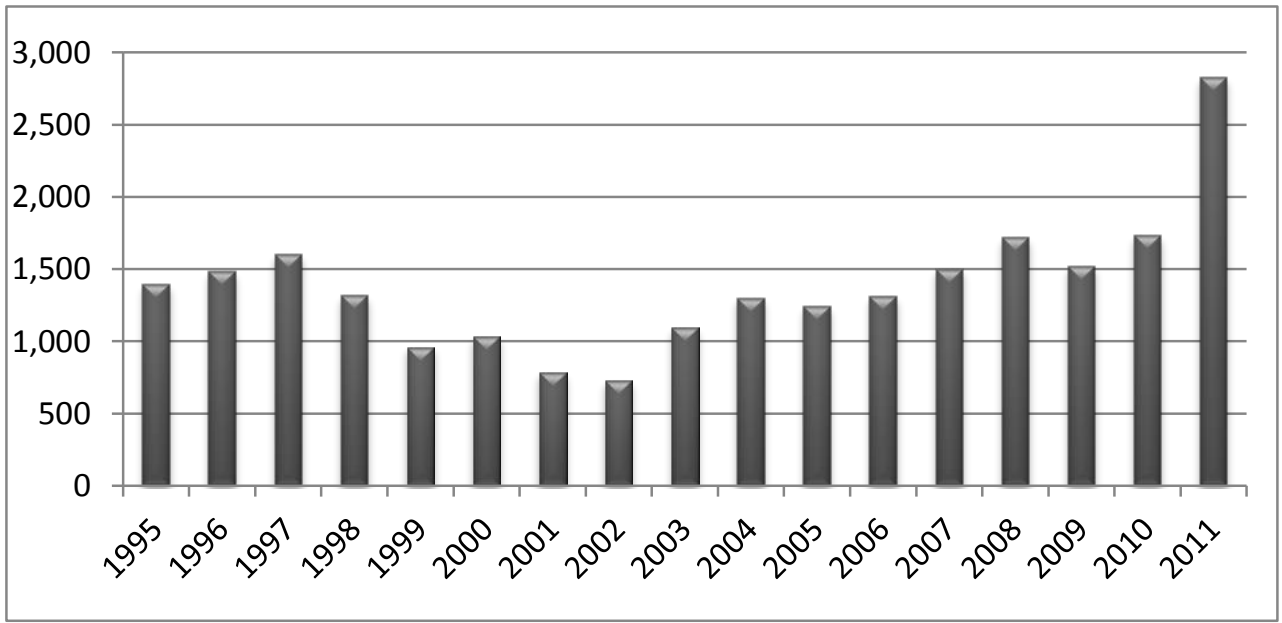

Fonte: elaboração própria a partir de FAO (2013)

O comportamento do valor da produção está diretamente relacionado à área colhida, além disso, este indicador é explicado pela variação nos preços no mercado internacional que, por sua vez, sofre influência das variações na oferta, demanda e dos estoques de algodão mundial. 
A Figura 5 expõe a evolução da distribuição da área colhida por Grande Região. A série apresenta algumas particularidades que cabem ser exploradas. No início do período considerado, a liderança em área colhida era ocupada pela Região Sul e seguida pela Região Nordeste do país. No período anterior a 1996 competia ao Estado do Paraná a maior expressividade em área de algodão no Brasil que, em meados dos anos 1980, representou $39 \%$ da quantidade produzida nacionalmente. A partir de 1997 ocorreu uma inversão locacional do cultivo de algodão, que passou a ser dinamizado pela Região Centro-Oeste do país, cenário que perdura até o período atual, destacando-se como a principal região produtora da fibra.

O Paraná registrou uma queda de 94,4\% na área plantada entre 1985 e 2003. Zimovski e Conceição (2004) explicam essa inversão a partir da intensificação da abertura comercial e da deterioração do crédito rural disponível aos produtores paranaenses. Aliado a esses fatores, o Centro-Oeste possui características edafoclimáticas e uma estrutura fundiária que otimiza economias de escala, além de disponibilizar incentivos fiscais para a comercialização da pluma.

Figura 5 - Produção de pluma de algodão por Grande Região (em mil toneladas)

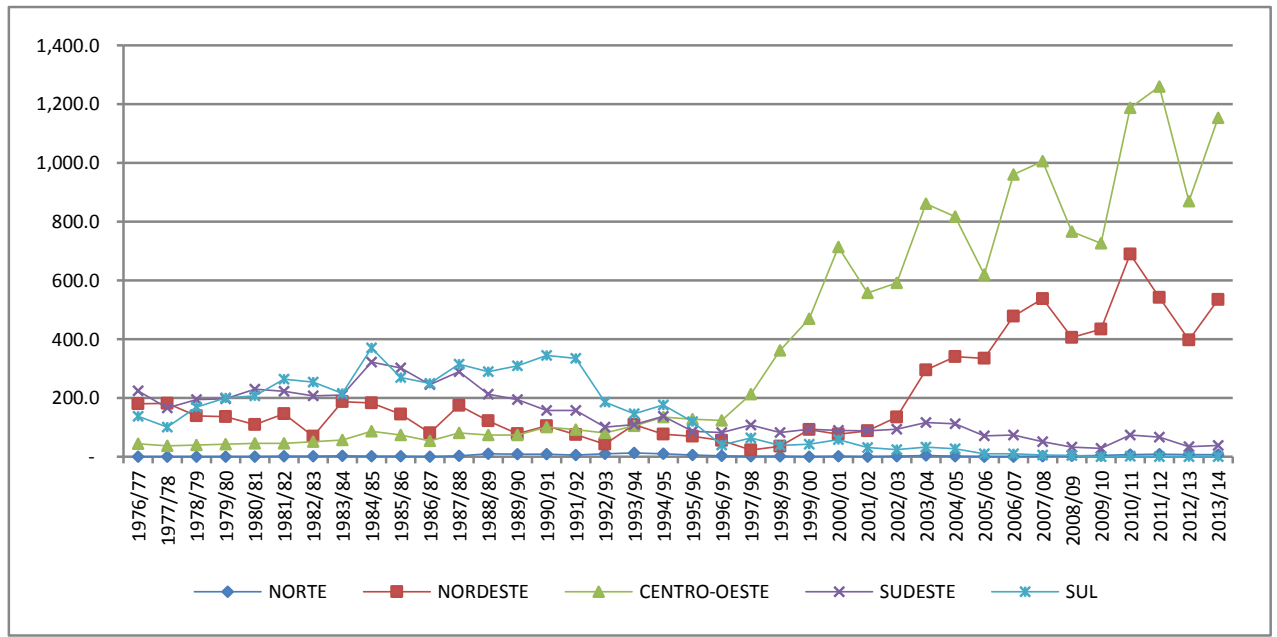

Fonte: elaboração própria a partir de dados históricos da Conab (2014)

Entre as Unidades Federativas da região Nordeste, destaca-se a Bahia, que figura entre os maiores produtores de algodão do país, com avanços na produção na região Oeste do Estado. Embora apresente uma evolução cíclica no período analisado, a quantidade produzida de algodão no Brasil possui uma tendência crescente, como pode ser observado nas informações dispostas na Figura 6. Destaca-se ainda nesta análise, a evolução das exportações brasileiras da pluma, que totalizaram um incremento de cerca de 600\% entre 1990 e 2011.

Figura 6 - Quantidade produzida e exportações brasileiras de algodão 1990-2011 




Fonte: elaboração própria a partir de FAO (2013) e IBGE (2013)

No tocante ao comércio internacional, dados da FAO (2013) apontam que em 2011 os Estados Unidos ocuparam a liderança nas exportações mundiais com uma representatividade de mercado de $34 \%$; o segundo maior exportador foi a Índia com 23\% dos embarques; a Austrália representou o terceiro maior no ranking mundial com $10 \%$ de participação total, cifra muito próxima do quarto maior exportador, o Brasil, com 9\% dos embarques mundiais. Esses índices ilustram a dinâmica do setor, com alta concentração de mercado e liderança dos Estados Unidos nas exportações de algodão, o que confere influência sobre o equilíbrio dos preços da commodity (FERREIRA FILHO; ALVES; VILLAR, 2009).

A Figura 7 apresenta os maiores mercados consumidores mundiais da fibra de algodão em 2011. Observa-se que o mercado asiático é o principal destino das exportações mundiais, com uma representatividade de mais de $50 \%$ do volume total. Os dados demonstram a liderança chinesa como o mais expressivo demandante mundial de algodão, refletindo a dinâmica de sua indústria têxtil (FAO, 2013).

Figura 7 - Maiores mercados compradores de algodão mundial em 2011(em toneladas) 


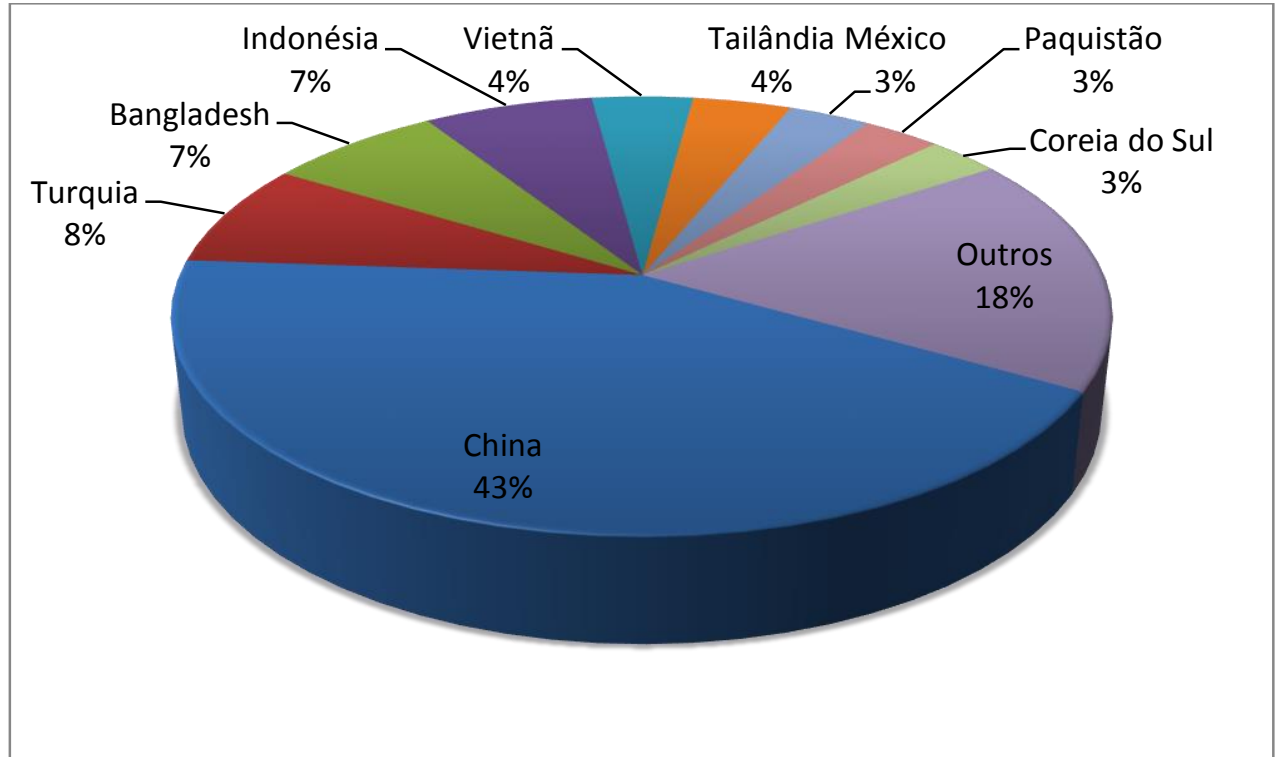

Fonte: elaboração própria a partir de FAO (2013)

Conforme apontam Ferreira Filho, Alves e Villar (2009) o Brasil destaca-se em competitividade no algodão devido à produtividade elevada, entretanto, os custos de produção, sobretudo os variáveis, são altos por hectare produzido. Para se elevar a competitividade do país são necessários novos investimentos em tecnologia que minimizem os custos de produção, uma vez que a elevação da produtividade é uma variável mais rígida, haja vista que o Brasil já possui uma das maiores do mundo, dificultando progressos significativos nesse aspecto.

\section{A MUDANÇA ESTRUTURAL NO SETOR COTONICULTOR}

Como exposto anteriormente, em virtude de eventos exógenos a determinado contexto em análise é presumível a averiguação de quebras estruturais em determinados modelos de regressão envolvendo séries de tempo, de modo que se constate uma mudança estrutural na relação entre a variável dependente e as variáveis explicativas. Um evento exógeno pode ser qualquer acontecimento externo que cause uma mudança estrutural nos valores dos parâmetros do modelo considerado, de forma que os mesmos não se mantenham iguais durante determinado período (SULIANO; CAVALCANTE; ROCHA, 2009).

Neste estudo, o evento exógeno ao setor cotonicultor presumível de promover uma quebra estrutural nas séries de tempo referentes à quantidade produzida e ao volume exportado de algodão brasileiro é a ação movida pelo Brasil na OMC, em setembro de 2002, contra as medidas protecionistas adotadas pelos EUA para o setor em discussão, denominada contencioso do algodão.

A fim de identificar essa possível mudança estrutural procedeu-se o teste de Chow. Conforme apresentado na Tabela 1, pode-se afirmar que o contencioso do algodão produziu no período em análise uma mudança estrutural tanto na quantidade produzida (QPA) quanto no volume exportado de algodão (VEA), abrindo espaço para uma nova configuração no setor cotonicultor brasileiro.

Tabela 1 - Teste de Chow para quebra estrutural* 


\begin{tabular}{ccc} 
Variáveis & Estatística Fcalculado & p-valor \\
\hline QPA & $3,059^{* *}$ & 0,071858 \\
VEA & $28,501^{* * *}$ & 0,000003 \\
\hline
\end{tabular}

* Os pressupostos de normalidade e independência dos resíduos dos subperíodos estão contemplados.

**Considerando o nível de significância de 10\%, Fcalculado> F crítico , logo rejeita-se H0.

*** Considerando o nível de significância de 5\%, Fcalculado> F crítico , logo rejeita-se H0.

Fonte: dados do estudo.

Considerando que o teste de Chow apenas infere que os parâmetros das regressões em análise são diferentes, este estudo considerou a presença de variáveis dummy, permitindo então fazer inferências relacionadas à natureza dessa diferença, ou seja, se essa diferença decorre dos interceptos, dos coeficientes angulares ou de ambos. Para tanto, a variável Mudança corresponde à mudança de intercepto e Tempo*Mudança a mudança de inclinação. Os resultados estão descritos na Tabela 2.

Tabela 2 - Modelo de quebra estrutural para QPA e VEA.

\begin{tabular}{|c|c|c|c|c|c|}
\hline & Variáveis & Coeficientes & Desvio-padrão & Estatística t & $\begin{array}{l}\text { p- } \\
\text { valor }\end{array}$ \\
\hline & $\beta_{0}$ & $1.468 .200,00$ & $362.013,70$ & 4,05 & 0,0007 \\
\hline & Tempo & $16.085,47$ & $55.749,42$ & 0,29 & 0,7762 \\
\hline & Mudança & - 999.608,60 & $1.281 .469,00$ & $-0,78$ & 0,4455 \\
\hline & Tempo*Mudança & $160.004,50$ & $92.169,37$ & 1,73 & 0,0997 \\
\hline & $R^{2}$ & 0,72 & & & \\
\hline & $\mathrm{R}^{2}$ ajustado & 0,67 & & & \\
\hline & Estatística F & 15,46 & & & \\
\hline$=$ & $\mathrm{p}$-valor de F & 0,000032 & & & \\
\hline & $\beta_{0}$ & $54.997,09$ & $33.791,95$ & 1,63 & 0,121 \\
\hline & Tempo & - 2.346,58 & $5.203,90$ & $-0,45$ & 0,6574 \\
\hline & Mudança & $-611.827,50$ & $119.617,90$ & $-5,11$ & 0,0001 \\
\hline & Tempo*Mudança & $60.576,65$ & $8.603,49$ & 7,05 & 0,0000 \\
\hline $\mathbb{4}$ & $R^{2}$ & 0,93 & & & \\
\hline & $\mathrm{R}^{2}$ ajustado & 0,92 & & & \\
\hline II & Estatística F & 85,63 & & & \\
\hline 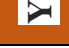 & $\mathrm{p}$-valor de $\mathrm{F}$ & 0,0000 & & & \\
\hline
\end{tabular}

Fonte: dados do estudo

Ao avaliar os coeficientes para o período pós-2002 nota-se uma mudança estrutural para o volume exportado de algodão, balizada pela significância dos coeficientes angulares da variável Mudança e da interação Tempo*Mudança. Ou seja, após 2002 houve uma mudança significativa no comportamento do volume exportado, identificada pela modificação do intercepto e da inclinação da função tendência da variável dependente em questão, resultado que pode ser associado com os efeitos do contencioso do algodão.

Por outro lado, o coeficiente angular da variável Mudança para o comportamento da quantidade produzida de algodão não se mostrou significativo, porém ao longo do tempo os efeitos da mudança estrutural e, intuitivamente da ação movida pelo Brasil na OMC contra as medidas 
protecionistas adotadas pelos EUA para o setor em discussão, tornam-se aparentes, o que pode ser verificado pela significância, a 10\%, da variável interação Tempo*Mudança.

Diante do acirramento da concorrência externa e da inferioridade competitiva frente aos EUA, o Brasil investiu em novas tecnologias e alterou a configuração espacial da produção, deslocando-a de antigos espaços produtores hegemônicos (São Paulo e Paraná, por exemplo) para uma nova territorialização no Mato Grosso e na Bahia a fim de obter economias de escala, fato evidenciado no incremento expressivo da produtividade entre 1998 e 2011 (IBGE, 2013). Essa mudança positiva conquistada pelo setor cotonicultor também pode ter sido favorecida por uma tendência do cenário agrícola geral. Conforme Oliveira (2014):

(...) o Brasil realizou uma transição bem-sucedida de transformação da produção agrícola em várias commodities, passando de importador líquido de alimentos, na década de 1960, para produtor estratégico, em 2014. Desde a década de 1990, enquanto a produção mundial apresentava estagnação produtiva, a agricultura brasileira mostrava-se dinâmica e em crescimento (OLIVEIRA, 2014).

De certa forma, o teste de Chow complementa a descrição conjuntural previamente realizada e elucida outros estudos empíricos, além de dar respaldo à mudança estrutural ocorrida no setor tendo como ponto de referência a abertura do contencioso na OMC. Além disso, destaca-se que o espaço mundial, sob o ponto de vista de Castells (1999), está associado a uma nova ordem econômica mais informacional e global, como resultado do desenvolvimento tecnológico, onde o processo tecnológico informacional cria a competividade e o aumento da produtividade, descrevendo trajetórias territoriais próprias, diferenciando e excluindo países e regiões que não dominam a tecnologia.

Em efeito, o presente artigo ilustra a reestruturação espacial do setor, a solidificação do mesmo no cenário produtivo brasileiro e no âmbito internacional, bem como os ganhos advindos do contencioso do algodão, evidenciando o esforço do setor em questão em não ser suprimido por uma ordem econômica mais informacional e global. Todavia, um sistema produtivo nas bases do meio técnico-científico-informacional, que corresponda aos processos de transformação da natureza e de construção do espaço geográfico e organizacional no Mato Grosso e Bahia, modifica as relações da produção nas áreas de expansão e de abrangência. Assim, além de um novo padrão técnico há uma tendência crescente do espaço de se readequar, modificando as estruturas econômicas, sociais e culturais (SANTOS, 2008). Como observado:

(...) no curso das mudanças na cotonicultura brasileira, observa-se não somente o deslocamento espacial da produção em direção aos cerrados, como também a difusão de novos métodos, técnicas e gerenciamento da produção (RAMOS; CASTILLO, 2010).

Em função disso, o precedente perfil do cotonicultor, majoritariamente formado por pequenos produtores familiares, é substituído pela grande propriedade e pelos empresários rurais capitalizados. Estes são pressionados a aumentar os ganhos em escala de suas lavouras e a inserir-se de forma cada vez mais plena na lógica do capital financeiro. 
Da mesma forma como participam da criação de novos processos vitais e da produção de novas espécies (animais e vegetais), a ciência e a tecnologia, junto com a informação, estão na própria base da produção, da utilização e do funcionamento do espaço e tendem a constituir o seu substrato (SANTOS, 1999).

A divisão do trabalho, movida pela produção, é o motor da diferenciação espacial, ao atribuir, a cada modificação sua, novos conteúdos e funções aos lugares; hoje, o que impulsiona a divisão internacional do trabalho é a informação, cujo resultado é a divisão territorial do trabalho. Para o autor, o valor real de um recurso (seja ele população, produto, dinheiro ou inovação) depende de sua qualificação geográfica, da "(...) significação conjunta que todos e cada qual obtêm pelo fato de participar de um lugar" (SANTOS, 2002).

Ainda em relação às subvenções americanas, o artigo consegue expor os efeitos negativos destas no setor cotonicultor brasileiro, uma vez que as receitas de exportação do algodão brasileiro foram afetadas significativamente, principalmente entre 1999-2002, período em que o algodão norte-americano recebeu subvenções no valor de US\$ 12,5 bilhões, decorrentes do programa de subsídios para sua produção (LIMA, 2006; ABRAPA, 2007).

Essas subvenções para a produção de algodão dos EUA têm a intenção de criar um cenário de competitividade artificializado, controlando assim os preços do algodão no mercado internacional, haja vista que os custos de produção nos Estados Unidos são relativamente altos e sua produtividade é inferior à brasileira, o que permite concluir que não há outro fator amparando o desempenho competitivo apresentado pelo setor cotonicultor americano que não seja as compensações financeiras (FERREIRA FILHO; ALVES; VILLAR, 2009).

Cabe ressaltar que estas subvenções não se aplicam exclusivamente ao algodão, ocorrem praticamente com a totalidade dos produtos agrícolas, gerando consequências danosas, principalmente para os países em desenvolvimento. Importante frisar que é sobre essa influência sobre os preços e, por consequência, no volume de comércio a principal pauta do questionamento apresentado pelo Brasil, em setembro de 2002, junto a Organização Mundial do Comércio (DAL PAl, et. al, 2014).

Com o intuito de evitar as retaliações impostas pela OMC, resultantes da ação movida pelo Brasil, em 2010 os Estados Unidos propuseram um acordo compensatório ao país até que a Lei Agrícola norte-americana (Farm Bill) fosse modificada. Dentre as questões negociadas, pode-se destacar a criação de um fundo de apoio aos cotonicultores afetados pelos subsídios americanos. Os recursos desse fundo seriam utilizados para investimentos em capacitação, assistência técnica, combate a pragas e outros, incorrendo em benefícios à cotonicultura nacional como um todo.

Ainda em relação aos efeitos das medidas protecionistas americanas e os impactos do contencioso do algodão no setor cotonicultor, Dal Pai et. al.(2014) ressaltam que praticamente durante todo o período de 1995 a 2010 as exportações americanas de algodão perceberam um maior nível de competitividade em relação às brasileiras. De forma complementar, com base no índice de vantagens comparativas reveladas, os autores ressaltam que entre 1995 e 2000 a posição do Brasil estava muito aquém dos Estados Unidos no que se refere à competitividade da commodity referenciada, denotando que o Brasil não 
foi competitivo, naquele período, no setor cotonicultor. A partir de 2001, o Brasil apresenta sensível incremento no índice, admitindo-se a sua condição de competitividade internacional no algodão. Conforme observado:

(...) no período 1997-2005 há uma espetacular reversão da tendência de queda com a produção brasileira alcançando 1,3 milhão de toneladas $(+324,8 \%)$. Mas agora não mais com base no algodão meridional, esse perdeu a hegemonia interna para a nova cotonicultura de grandes lavouras mecanizadas do Cerrado, portanto uma reversão estruturalmente distinta (...) (GONÇALVES; RAMOS, 2008).

A nova configuração do setor cotonicultor pós-contencioso do algodão também é evidenciada por Dal Pai, et. al.(2014). De acordo com os autores, o valor da produção de algodão em 2011 no país superou em 76\% o valor da produção do período anterior, evidenciando um cenário de recuperação associado aos preços internacionais e ao volume produzido. De certa forma, o estudo demonstrou ligeira recuperação, potencializada após 2010 quando o preço da commodity percebeu incremento significativo. A partir dessa verificação, pode-se induzir que as exportações brasileiras são mais sensíveis às oscilações no mercado internacional, sendo diretamente afetadas pela variação nos preços externos (ALVES, 2005).

No cenário atual (2013), a alta dos preços do algodão minimizam os efeitos perversos das subvenções americanas, contudo, caso os preços voltem a cair, os preços mínimos assegurados na Farm Bill, provocariam novamente sérias perturbações para os países menos desenvolvidos, como o Brasil e os do Oeste Africano, diretamente dependentes desse produto. Diante disso, acredita-se que o contencioso trouxe reflexos positivos para a política econômica e comercial brasileira, embora existam ainda muitas outras conquistas que são fundamentais quando o assunto é política agrícola brasileira, para o crescimento econômico do País em sua totalidade.

\section{CONSIDERAÇÕES FINAIS}

O escopo deste estudo foi abordar a territorialização da cotonicultura e os impactos do contencioso do algodão na configuração do setor no Brasil, a partir da possível mudança estrutural evidenciada por estudos empíricos. Para viabilizar esta análise descreveu-se a natureza da trajetória histórica da cotonicultura no Brasil, analisou-se a existência de uma mudança estrutural no setor cotonicultor brasileiro tendo como referência a abertura do contencioso na OMC e finalmente, identificaram-se algumas alterações na configuração da cotonicultura brasileira.

A discussão apresentada evidenciou o significativo avanço da participação brasileira na oferta mundial de algodão, bem como expressaram a crescente ampliação do mercado internacional para o produto brasileiro. Os avanços decorreram da intensificação do uso de tecnologias e investimentos em qualidade da fibra que, além de elevarem a produtividade nacional viabilizando economias de escala, nortearam novos mercados e ampliaram as conexões estabelecidas com outras nações. 
Conforme verificado a partir da estimação do teste de Chow, a abertura do contencioso contra os EUA na OMC provocou uma mudança estrutural tanto na quantidade produzida (QPA) quanto no volume exportado de algodão (VEA), admitindo-se o estabelecimento de uma nova configuração no setor cotonicultor brasileiro. Tal constatação decorre da significância estatística dos coeficientes angulares da variável Mudança e da interação Tempo*Mudança sugerindo que após 2002 ocorreu uma mudança significativa no comportamento do volume exportado, admitindo-se associação com os efeitos do contencioso do algodão.

Os resultados obtidos para a variável quantidade produzida de algodão não permitiram estabelecer correlação com a variável Mudança. Contudo, os efeitos da mudança estrutural evidenciaram-se ao longo da série, uma vez que, considerando um nível de significância de 10\%, a variável interação Tempo*Mudança foi significativa no modelo.

Diante do impasse entre Brasil e EUA, percebeu-se que aquele país procurou novas formas de ampliar sua participação no mercado internacional do algodão, pois mesmo diante da supremacia americana, decorrente da concessão de subvenções à produção e comercialização, o Brasil alterou a configuração estrutural do setor ampliando a produção e a participação no comércio mundial do algodão.

Em suma, o presente artigo ilustra a reestruturação espacial do setor, a solidificação do mesmo no cenário produtivo brasileiro e no âmbito internacional, bem como os ganhos advindos do contencioso do algodão, evidenciando o esforço do setor em questão em não ser suprimido por uma ordem econômica mais informacional e global. 


\title{
Structural change in Brazilian sector cotton- grower: An analysis of the Brazilian cerrado and territorial impact of the cotton dispute
}

\begin{abstract}
This study aimed at discussing the new territorialization of Brazilian cotton production, from the collapse in the 1990s, making use of the theory of technical-scientificinformational means to investigate a possible regional and structural change in the sector after 2002, mainly due to the action brought by Brazil at the WTO called the cotton dispute against the subsidies adopted by the US in the production of this commodity. To accredit these results, it was used the Chow test in order to verify the structural change in quantity produced and exported volume of Brazilian cotton, with the hypothesis of identifying the year in which the institutional rupture occurred. Within this context it was attested the change of structure, especially in the exported volume of cotton from the year in question and a reorganization of productive space in the formation of a new territory built for the Brazilian cotton culture.
\end{abstract}

KEYWORDS: International Trade Litigation cotton. Structural Break. Territorialization. Techno-Scientific-Informational milieu. 


\section{REFERÊNCIAS}

ABRAPA. Associação Brasileira dos Produtores de Algodão. 2007. Disponível em: $<$ www.abrapa.com.br>. Acesso em 12 de agosto de 2013.

ALVES, L. R. A. Estrutura de custos de produção de algodão no Brasil em diferentes regiões. In: V Congresso brasileiro do algodão. Cuiabá-MT, 2005. Disponível em:

<www.cnpa.embrapa.br/produtos/algodao/publicacoes/trabalhos cba5 $>$. Acesso em: 28 ago. 2013.

CARLOS, A. F. A. O lugar no/do mundo. 2007.São Paulo: FFLCH, p.85.

CASTELLS, M. A sociedade em rede - a era da informação: economia, sociedade e cultura. v. 1. Trad. Roneide Venâncio Majer e Jussara Simões. 1999. São Paulo: Paz e Terra. p. 617.

CHOW, G. Tests of equality between sets of coefficients in two linear regressions. Econometrica, n. 28, p. 591-605. 1960.

COSTA, S. R.; BUENO, M. G. A Saga do Algodão: das primeiras lavouras à ação na OMC. Rio de Janeiro: Insight Engenharia, p.144.2004.

DAL PAI, C.; BRAUN, M. B. S.; STRASSBURG, U.; OLIVEIRA, N. M. Política comercial e competitividade das exportações brasileiras de algodão: uma reflexão sobre o contencioso na OMC. In: 52 CONGRESSO DA SOCIEDADE BRASILEIRA DE ECONOMIA, ADMINISTRAÇÃO E SOCIOLOGIA RURAL, 2014. Goiânia. Anais... Goiânia, 2014, 20p.

DIAS, J.; CASTRO JÚNIOR, V. J. de.Análise de quebra estrutural na formação bruta de capital fixo do Brasil. Economia, n. 29, p. 257-274. 2003.

FERREIRA FILHO, J. B. S.; ALVES, L. R. A.; VILLAR, P. M. D.Estudo da competitividade da produção de algodão entre Brasil e Estados Unidos - safra 2003/04. RESR, v. 47, n. 01, p.59-88. 2009.

FOOD AND AGRICULTURE ORGANIZATION (FAO).FAOStat. Disponível em: $<$ www.faostat.fao.org $>$. Acesso em: 10 ago. 2013.

GONÇALVES, J. S.; RAMOS, S. de F. Mudanças Estruturais na Produção de 
GUJARATI, D. M. Econometria Básica: 4ạ Ed. Rio de Janeiro. Elsevier. P. 812. 2006.

INSTITUTO BRASILEIRO DE GEOGRAFIA E ESTATÍ́STICA (IBGE). (2013) Sistema IBGE de Recuperação Eletrônica (SIDRA). Disponível em: <www.sidra.ibge.gov.br>. Acesso em: 12 ago. 2013.

LIMA, T. O contencioso do algodão: cenários para mudança na política de subsídios dos EUA. Rev. Bras. Polít. Int., v. 49, n. 01, p. 139-158. 2006.

JALES, M.How would a WTO Agreement on Cotton Affect Importing and Exporting Countries? ICTSD Programme on Agricultural Trade and Sustainable Development Issue (Paper No. 26) (may 2010), International Centre for Trade and Sustainable Development, Geneva, Switzerland. P. 48. 2010.

PAN, S.; MOHANTY, S.; ETHRIDGE, D.; FADIGA M. The Impacts of U.S. Cotton Programs on the World Market: An Analysis of Brazilian and West and Central African WTO Petitions. (Paper).Department of Agricultural and Applied Economics, Texas Tech University, Lubbock.p. 8.2004.

PEREIRA, C. T.; COSTA, V. M.; ARAÚJO, L. R. 100 Casos na OMC: a experiência brasileira em solução de controvérsias. Revista Política Externa, v. 20, n. 4, p. 7692. 2012.

MOREIRA, R. Para onde vai o pensamento geográfico? Por uma epistemologia crítica. São Paulo: Contexto. 191 p. 2008.

OLIVERIA, Andréa L.R. de.A logística do agronegócio: para além do "apagão logístico". p.337-369. Capítulo 6. 2014. IN: O mundo rural no Brasil do século 21: a formação de um novo padrão agrário e agrícola / Antônio Márcio Buainain, Eliseu Alves, José Maria da Silveira, Zander Navarro, editores técnicos. - Brasília, DF : Embrapa. 1182 p. 2014.

RAMOS, S. de F.; CASTILLO, R. Sistemas técnicos agrícolas do algodão e uso do território brasileiro. GEOGRAFIA, Rio Claro, v. 35, n. 1, p. 101-114, jan./abr. 2010.

SANTOS, R. F. dos; SANTOS, J. W.dos.Crise na cadeia produtiva do algodão. Revista de Oleaginosas e Fibrosas, Campina Grande, v.1, n.1, p.25-36. 1997.

SANTOS, M. Modo de produção técnico-científico e diferenciação espacial. 
. A Natureza do Espaço: técnica e tempo, razão e emoção. São Paulo:

EDUSP. 384p. 2002.

Por uma Geografia Nova: da crítica da geografia a uma geografia crítica.

6ạ ed. São Paulo: EDUSP. 288 p. 2004.

.Técnica, espaço e tempo: globalização e meio técnico científico informacional. 5a ed. São Paulo: EDUSP. 174 p. 2008.

SEN, A. Keep word on cotton subsidy else no global deal, US told. The Times ofIndia, 23 Juneof 2010. 2010.

SULIANO, D. C.; CAVALCANTE, A. L.; ROCHA, M. E. B. Mudança estrutural no setor exportador cearense: evidências empíricas a partir do teste de chow. Textos para Discussão n. 59. Instituto de Pesquisa e Estratégia Econômica do Ceará (IPECE), 10 p. 2009.

ZIMOVSKI, A. R.; CONCEIÇÃO, R. J.A evolução da cotonicultura no Brasil e no Paraná. Análise Conjuntural, v. 26, n. 9-10, p.15-27. 2004.

Recebido: 05 dez. 2015

Aprovado: 20 mar. 2016

DOI: $10.3895 /$ rbpd.v5n1.3623

Como citar: BARCHET, I.; ROCHA, A. A.; PAI, C. D. Mudança estrutural no setor cotonicultor brasileiro: Uma análise da territorialização no cerrado brasileiro e do impacto do contencioso do algodão. R. bras.

Planej. Desenv., Curitiba, v. 5, n. 1, p. 6-25, jan./abr. 2016. Disponível em:

$<$ https://periodicos.utfpr.edu.br/rbpd>. Acesso em: XXX.

Correspondência:

Isabela Barchet

Rua da Faculdade, 645, Jardim Santa Maria, Toledo, Paraná

Direito autoral: Este artigo está licenciado sob os termos da Licença Creative Commons-Atribuição 4.0

Internacional.

(c) (1) 